\title{
Degradation of Gas Turbine Blades for a Thermal Power Plant
}

\author{
Ahmad Afiq Pauzi, Norlia Berahim, and Shuib Husin \\ Materials Engineering Group, TNB Research Sdn Bhd, Kawasan Institusi Penyelidikan dan Latihan Bangi, 43000 Kajang, Selangor, \\ Malaysia
}

\begin{abstract}
There are three stages of gas turbine blade in hot gas path (turbine section) of power generation gas turbine. Occurrences of wear and crack were observed on gas turbine blades in this section. The blades are made of nickel base superalloy (GTD 111). Crack generally occurred at airfoil area of the blades while wear generally occurred at root area of the blades. The purpose of this study is to determine the degradation of two stages blades in the turbine section after being exposed to 24,000 running hours. The affected areas of the mating surfaces were analyzed through visual and microstructure testings and the type of degradation was discussed.
\end{abstract}

\section{Introduction}

Nickel base superalloys are widely used in applications exposed to high temperature and vibration such as hot gas path components in power generation gas turbine. Turbine blade is one of critical components in the turbine system. This component experienced temperature of $1000{ }^{\circ} \mathrm{C}$ in the gas turbine [1]. Wear and crack are the main problems of gas turbine blade [2]. The component experienced surface and materials degradation after 24,000 hours in service. Based on previous investigation of wear and crack on gas turbine blades, most blades suffer severe operation conditions characterized by the following factors: operation environment (high temperature) and mechanical action (relative movement between and forces between blade root and its supporters) [2].

In normal practice, the turbine blades are subjected to heavy repair processes thus increasing the cost of the refurbishment [3]. Detail analyses of wear and cracks on the components related to hardness, microstructure characteristics and wear mechanisms, and wear measurement have been considered to predict the wear characteristics of the components. Naeem et al had revealed through visual and metallurgical analysis, the surface of blades were very rough and experience crack and diversely colored (erosion wear) [4].

Detailed analysis is very crucial as it cannot be relied only to visual observation and measurement, but deep understanding in damage mechanisms, and wear microstructures in order to evaluate the severity of wear and crack. To date, there are many study conducted on gas turbine blades based on their design life of 72,000 hours. Bernstein had revealed that for gas turbine hot section components, wear and crack are most important for turbine hardware at their design life [5]. Karganejad et al had revealed the root of the blade is not exposed to hot combustion gasses; hence temperature in this section is much lower than the blade airfoil so the blade root is considered as cold section (reference zone) [6]. This study focuses on the degradation of gas turbine blades, which have been taken out at the earlier than their design life, which is at 24,000 hours for visual and microstructure evaluation.

\section{Starting materials}

The turbine blades that were under evaluation were taken from a 97MW gas turbine. Figure 1 and 2 show the location of airfoil and root on gas turbine first stage and second stage. These areas were selected due to occurrence of wear and crack based on findings by Karganejad et al. [6].

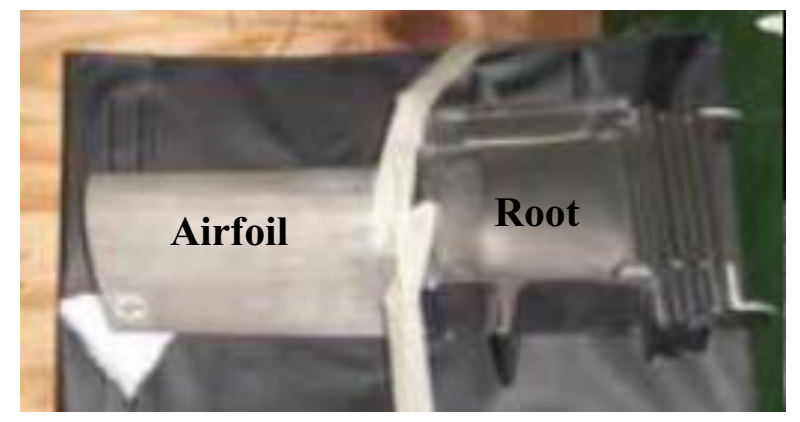

Figure 1. First Stage Blade 


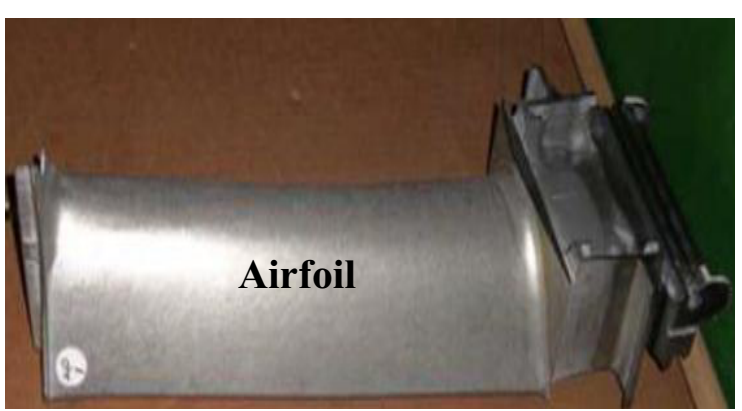

Figure 2. Second Stage Blade

\section{Visual observation and microstructure}

The visual observation was carried out after the blades had been operating 24,000 hours of operation. The turbine blades are made of a nickel base GTD 111 [11]. The chemical composition result for the turbine blades is shown in Table 1 . These results are the average from 3 points in turbine blades. The table also includes the standard chemical-composition data for GTD 111.

Table 1. Chemical composition of GTD 111 turbine blade

\begin{tabular}{c|cccccccccc} 
Element & $\mathbf{C r}$ & $\mathbf{N i}$ & $\mathbf{C o}$ & $\mathbf{F e}$ & $\mathbf{W}$ & $\mathbf{T a}$ & $\mathbf{T i}$ & $\mathbf{M o}$ & $\mathbf{Z r}$ & $\mathbf{A l}$ \\
\hline GTD 111 & 14.22 & 61.05 & 9.68 & 0.85 & 4.42 & 3.12 & 4.32 & 1.72 & 0.10 & 0.00 \\
\hline
\end{tabular}

The microstructures of the turbine blades were recorded before and after its removal from the gas turbine.

\section{Result and discussion}

\subsection{Visual observation}

Table 2. Visual observation and microstructures of gas turbine blades

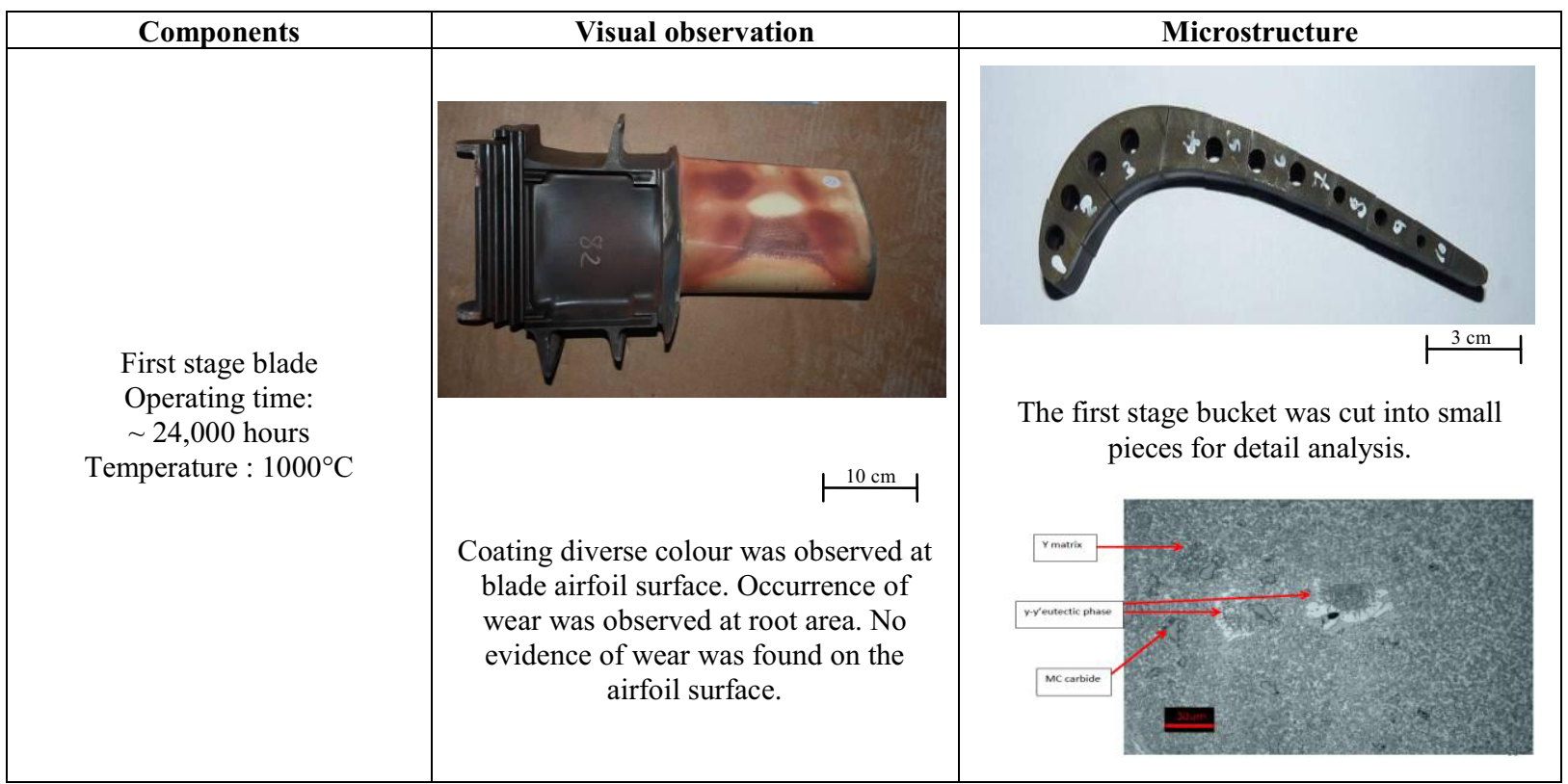




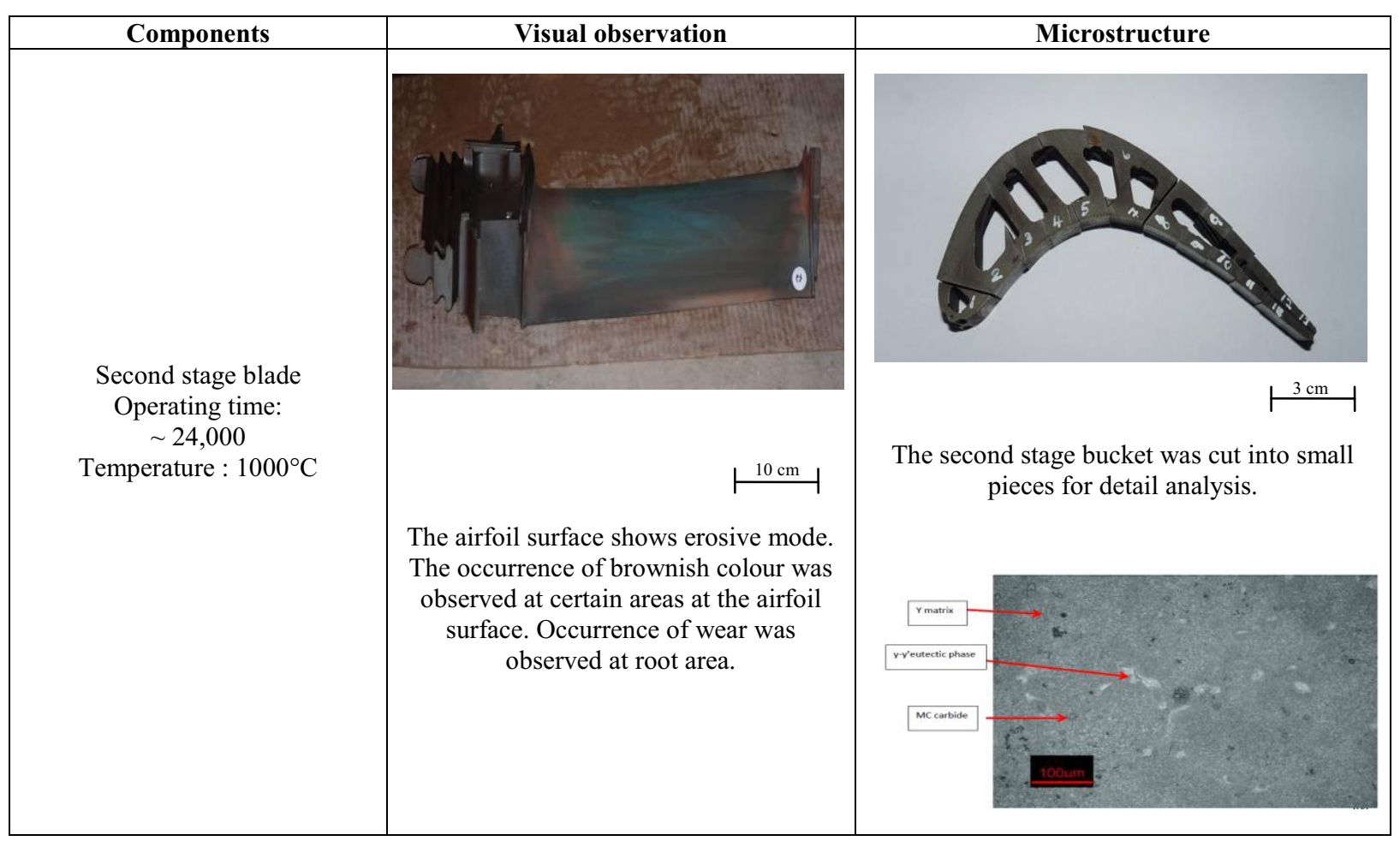

Generally, the blades are physically in good condition with no evidence of crack, oxidation or foreign object damage at the airfoil area. Vishwanathan revealed that the exposure to high temperature produced significant symptom that can initiate crack [2]. The occurrence of wear was observed at root area. Materials loss with the evidence of discolored arising was observed on these areas. Only little wear debris was retained on the surfaces $[8,9]$. At these stages of damage, re-application of aluminum seal strip coating on the root area and application of thermal barrier coating (TBC) on airfoil area can protect the blades by affecting wear and crack mitigation [10].

\subsection{Microstructure examination}

Hyun In Kim et al revealed that when the gas turbine blades is used at high temperature for a long time, base material become damage and heat treatment has been applied of the elimanitation of cavities and cracks. [11]. Similar result had been revealed by Vardar et al, the crack initiated from the grain boundaries and propagated to the critical length. [12]. From this study, the morphology of the microstructures of gas turbine first stage and second stage blades are similar for nickel based alloy. The microstructure show fine $\gamma$ and $\gamma-\gamma$ ' eutectic form in the matrix and coarse random cubic or script morphology $\mathrm{MC}$ carbide in mainly distribute in the matrix. No creep void and degradation were observed. Current practices of maintaining the microstructure to meet blade's design life of 72,000 hours, thermal barrier coating on was applied on the blades to make them last longer when operating at high temperature [13].

\section{Conclusion}

Based on microstructure analysis that has been performed, no observation of crack and degraded microstructure on the samples. If the turbine blades were decided to be re-installing into gas turbine, based on microstructure analysis, the blades are recommended to be in service for next 24,000 hours operating time.

Based on the wear mode that has been observed on the components, the main wear mechanism on the turbine blades is fretting wear.

\section{References}

1. Cyrus B. Meher Homji and George Gabriles, Gas Turbine Blade Failures - Causes, Avoidance, and Throubleshooting, Bechtel Corporation, Texas

2. R Vishwanathan, Damage Mechanisms and Life Assessment of High Temperature Components, Electric Power Research Institute (EPRI)

3. R Rajendran, MD Ganeshanchar, Jivankumar, T. Mohana Rao, Condition Assessment of Gas Turbine Blades and Coatings, Engineering Failure Analysis, 2011

4. Mehdi Tofighi Naeem, Seyed Sli Jazyeri, Nesa Rezamahdi, KN Toosi, Failure Analysis of Gas Turbine Blades, Univerisity of Technology.

5. Henry L. Bernstein, Materials Issue for Users of Gas Turbines.

6. S. Kargarnejad, F. Djvanroodi, Failure assessment of Nimonic 80A turbine blade, Engineering Failure Analysis, 2012.

7. TNBR Qats Sdn Bhd, Technical Report on F-Class Materials Identification, 2013

8. J Blau, Friction and Wear Transitions of Materials, Noyes Publication, NJ 1989

9. R.G Bayer, Wear Analysis for Engineers, HNB Publishing, New York, 2002 
10. GE Energy Part and Services, Gas Turbine Condition Report, 2012

11. Hyun Ick Kim, Hong Sun Park, Jae Maen Koo, Chang Sung Seok, Sung Ho Yang, Moon Young Kim, Microstructural Investigation of GTD 111 DS Materials in The Heat Treatment Conditions
12. N Vardar, A Ekirim, Failure Analysis of Gas Turbine Blade In a Thermal Power Plant, Engineering Failure Analysis, 2007.

13. David R Clarke, Matthias Oechsner, and Nitin P Padture, Thermal Barrier Coating for More Efficient Gas Turbine Engines, Materials Research Society, 2012. 